\title{
Phloretin Modulates Human Th17/Treg Cell Differentiation In Vitro via AMPK Signaling
}

\author{
Ao Jiao $\mathbb{D}^{1},{ }^{1}$ Zhaoming Yang, ${ }^{2}$ Xibo Fu, ${ }^{1,2}$ and Xiangdong Hua $\mathbb{D}^{1}$ \\ ${ }^{1}$ Department of Hepatopancreatobiliary Surgery, Cancer Hospital of China Medical University, Liaoning Cancer Hospital \\ \& Institute, Shenyang, China \\ ${ }^{2}$ Department of Hepatobiliary Surgery, The First Hospital of China Medical University, Shenyang, China
}

Correspondence should be addressed to Xiangdong Hua; lnzl_hxd@163.com

Received 18 February 2020; Revised 2 July 2020; Accepted 15 July 2020; Published 29 July 2020

Academic Editor: Xiupeng Wang

Copyright (c) 2020 Ao Jiao et al. This is an open access article distributed under the Creative Commons Attribution License, which permits unrestricted use, distribution, and reproduction in any medium, provided the original work is properly cited.

Context. The imbalance between $\mathrm{T}$ helper 17 (Th17) cell and regulatory $\mathrm{T}$ (Treg) cell is involved in many immune disorders and diseases. Phloretin, a dihydrochalcone structural flavonoid compound, possesses many bioactive properties. However, whether phloretin could impact on the differentiation of $\mathrm{T}$ cells is not completely clear. Objective. We conducted studies to explore the effect of phloretin on glucose uptake, proliferation, and differentiation of human peripheral blood $\mathrm{CD}^{+} \mathrm{T}$ cells and investigated the mechanism of phloretin on inducing Th17/Treg development. Methods. Naïve CD4 ${ }^{+} \mathrm{T}$ cells were purified from peripheral blood of healthy volunteers, stimulated with anti-CD3/CD28 antibodies, and polarized in vitro to generate Th17 or Treg cells. Glucose uptake, proliferation, cell cycle, protein expression (phospho-Stat3, phospho-Stat5), and Th17 and Treg cell numbers were analyzed by flow cytometry. AMP-activated protein kinase (AMPK) signaling was analyzed by western blot. Results and Discussion. Phloretin could inhibit the glucose uptake and proliferation of activated $\mathrm{CD}^{+} \mathrm{T}$ cells. The proliferation inhibition was due to the G0/G1 phase arrest. Phloretin decreased Th17 cell generation and phospho-Stat3 expression as well as increased Treg cell generation and phospho-Stat 5 expression in the process of inducing Th17/Treg differentiation. The phosphorylation level of AMPK was significantly enhanced, while the phosphorylation level of mTOR was significantly decreased in activated $\mathrm{CD}^{+} \mathrm{T}$ cells under phloretin treatment. The AMPK signaling inhibitor compound $\mathrm{C}$ (Com C) could neutralize the effect of phloretin, while the agonist 5-aminoimidazole-4-carboxamide ribonucleotide (AICAR) could impact the Th17/Treg balance similar to phloretin during Th17/Treg induction. Conclusion. Our results suggest that phloretin can mediate the Th17/Treg balance by regulating metabolism via the AMPK signal pathway.

\section{Introduction}

Phloretin is a dihydrochalcone, a type of natural phenol. It can be found in apple tree leaves [1]. Phloretin has various bioactive properties, including antioxidant effects [2], protection of the skin from ultraviolet light-induced damage [3], anticancer activity $[4,5]$, antibacterial activity $[6,7]$, antidiabetic activity [8], and prevention of cardiovascular disease [9, 10]. In addition to these activities, phloretin has been shown to suppress the production of inflammatory mediators such as cytokines, chemokines, and differentiation factors induced by leukocytes, which are stimulated during the innate immune response [11]. Moreover, phloretin has been shown to suppress Toll-like receptor 2- (TLR2-) induced inflammation as a potent natural TLR2/1 inhibitor [12].

Treg and Th17 cells are subsets of the $\mathrm{CD} 4^{+} \mathrm{T}$ cell compartment that are important modulators of the innate and adaptive immune systems. [13] Th17 cells are a subset of proinflammatory $\mathrm{T}$ helper cells defined by their production of interleukin 17 (IL-17) which mediates powerful effects on stromal cells, resulting in the production of inflammatory cytokines and recruitment of leukocytes, especially neutrophils, thus creating a link between innate and adaptive immunity [14]. Th17 cells play an important role in tumor immunity, and the antitumor effect of infused Th17 cells has been confirmed in animal models [15]. On the contrary, 
Treg cells are formerly known as suppressor T cells, which are immunosuppressive and generally suppress or downregulate induction and proliferation of effector T cells [16]. It is now well substantiated that a large number of Treg cells infiltrate into tumor tissues of various cancers and their abundant presence is often associated with poor clinical prognosis [17].

The differentiation and function of $\mathrm{T}$ cell subsets are closely related to cell metabolism [18, 19]. Studies have shown that tumor microenvironment influences the differentiation of $\mathrm{T}$ cells by changing the metabolic phenotype of $\mathrm{T}$ cells [18]. Thus, $\mathrm{T}$ cell differentiation and function during disease can be controlled by regulating cellular metabolism.

Phloretin has been known as a potential anticancer drug, but whether phloretin could impact on the differentiation of $\mathrm{T}$ cells is not completely clear, and it remains unknown whether the functional outcome of phloretin on Th17/Treg cells is linked to cellular metabolism. In this study, we aim to determine the effect of phloretin on the differentiation of Th17/Treg and verify whether phloretin could influence the metabolic signaling of activated $\mathrm{CD} 4^{+} \mathrm{T}$ cells.

\section{Materials and Methods}

2.1. Drugs. Phloretin ( $\geq 98 \%$ by HPLC, Meilunbio, Dalian, China), 5-aminoimidazole-4-carboxamide ribonucleotide (AICAR) ( $\geq 98 \%$ by HPLC, Meilunbio), and compound C (Com C) (dorsomorphin, $\geq 98 \%$ by HPLC, Meilunbio) were solubilized for use in dimethyl sulfoxide (DMSO). In this study, control groups were treated with the same dose of DMSO. The final DMSO concentration was not more than $0.3 \%(v / v)$ and the same concentrations of DMSO were used between groups during drug treatment.

2.2. Cell Isolation and Sorting. Peripheral blood samples from healthy volunteers were collected in $10 \mathrm{~mL}$ anticoagulant tubes with four tubes per sample. Peripheral blood mononuclear cells (PBMCs) were isolated by 1077 (TBDscience, China) density gradient centrifugation. Cells harvested from the gradient interface were washed twice in PBS, counted, and immediately separated by the Human Naïve CD $4^{+} \mathrm{T}$ Cell Isolation Kit (STEMCELL, Canada). The purity of the isolated cells was $>95 \%$.

2.3. T Cell Culture and Polarization. The isolated naïve CD $4^{+}$ $\mathrm{T}$ cells were cultured in 96-well, U-bottomed plates at a concentration of $1 \times 10^{5}$ cells/well. Human T-Activator CD3/CD28 (Gibco, Norway) was added in culture medium overnight to activate $\mathrm{CD} 4^{+} \mathrm{T}$ cells. For Th17 cell polarization, activated $\mathrm{CD}^{+} \mathrm{T}$ cells were cultured with $20 \mathrm{ng} / \mathrm{mL}$ interleukin-6 (IL-6) (R\&D Systems), $2.5 \mathrm{ng} / \mathrm{mL}$ transforming growth factor beta-1 (TGF- $\beta 1$ ) (R\&D Systems), $2 \mu \mathrm{g} / \mathrm{mL}$ anti-IL-4 (R\&D Systems), and $2 \mu \mathrm{g} / \mathrm{mL}$ anti-interferongamma (IFN- $\gamma$ ) (Invitrogen). For Treg cell polarization, activated $\mathrm{CD}^{+}{ }^{+} \mathrm{T}$ cells were cultured with TGF- $\beta 1(2.5 \mathrm{ng} / \mathrm{mL}$, $\mathrm{R} \& \mathrm{D}$ systems) and IL-2 (10 ng/mL; BD Biosciences). Culture medium consisted of RPMI 1640 (Gibco, USA) supplemented with 10\% fetal bovine serum (FBS) (Gibco, Australia), $2 \mathrm{mM}$ L-glutamine (Solarbio, China), $1 \mathrm{mM}$ sodium pyruvate (Solarbio), $50 \mu \mathrm{M}$ beta-mercaptoethanol (Sigma-Aldrich,
USA), $1 \times$ nonessential amino acids (Sigma-Aldrich), $100 \mathrm{U} / \mathrm{mL}$ penicillin (Solarbio), $100 \mathrm{mg} / \mathrm{mL}$ streptomycin (Solarbio) and $10 \mathrm{mM}$ Hepes (Solarbio) [20, 21].

2.4. Glucose Uptake Assay. The cellular glucose uptake was measured using 2-(N-(7-nitrobenz-2-oxa-1, 3-diazol-4-yl) amino)-2-deoxyglucose (2-NBDG) (Invitrogen) incubation and flow cytometry (FACSCanto II, BD) as described previously [20]. The isolated naïve $\mathrm{CD}^{+} \mathrm{T}$ cells were cultured in 96-well plates at a concentration of $4 \times 10^{4}$ cells/well in $100 \mu \mathrm{L}$ culture medium with T-Activator (Gibco), overnight. The cells were then treated with or without phloretin $(25 \mu \mathrm{M}$, $50 \mu \mathrm{M}$, and $100 \mu \mathrm{M}$ ) (Sigma-Aldrich, USA) in $100 \mu \mathrm{L}$ glucosefree culture medium. After $30 \mathrm{~h}, 2-\mathrm{NBDG}$ was added at a final concentration of $100 \mu \mathrm{g} / \mathrm{mL}$ in glucose-free medium. After $16 \mathrm{~h}$, cultured cells were harvested and analyzed by flow cytometry [20]. And the geometric mean of FITC-A was taken as the mean fluorescence intensity.

2.5. Cell Proliferation Assays. The proliferation of naïve $\mathrm{CD}^{+}{ }^{+} \mathrm{T}$ cells was detected using CFSE Cell Proliferation Kit (Invitrogen). Freshly naïve CD4+ T cells $\left(2 \times 10^{6}\right.$ cells $\left./ \mathrm{mL}\right)$ were resuspended in CFSE (1:1000 dilution) staining solution for $20 \mathrm{~min}$ at $37^{\circ} \mathrm{C}$, protected from light. Then, the complete culture medium was added for $5 \mathrm{~min}$ to stabilize the CFSE staining. Cells were washed and resuspended in fresh, prewarmed complete culture medium with different treatments. After 4 days, cultured cells were harvested and analyzed by flow cytometry.

2.6. Cell Cycle Assays. To determine cell cycle distribution, 1 $\times 10^{5}$ cells were plated on a 96-well plate and then treated with various concentrations of phloretin for $48 \mathrm{~h}$. After treatment, the cells were washed twice with PBS and fixed in cold ethanol overnight and then incubated with propidium iodide and RNase A (Beyotime) for $30 \mathrm{~min}$ at $37^{\circ} \mathrm{C}$, protected from light. Thereafter, cells were analyzed by flow cytometry.

2.7. Flow Cytometry Analysis. Cells were harvested from plates and centrifuged, and the supernatants removed. PE anti-phospho-Stat3 antibody $\left(8119\right.$, CST) and Alexa Fluor ${ }^{\circledR}$ 647 anti-phospho-Stat 5 antibody $(9365$, CST) were used for staining T cells after polarization. Prior to Th17 cell detection, cells were incubated with Brefeldin A (Abcam) for 4-5h. FITC mouse anti-human CD4 antibody (555346, BD) and PE mouse anti-human IL-17A antibody (560486, $\mathrm{BD})$ were used for staining cells after polarization and treatment. For Treg cell detection, PE mouse anti-human CD25 (555432, BD), and Alexa Fluor 647 Mouse anti-Human Foxp3 (560045, BD) were used for staining cells after polarization and treatment. Flow cytometric detection was performed using BD FACSCanto II. Data were analyzed with FlowJo software (Tree Star Inc.).

2.8. Western Blot Analysis. Total cell lysates were analyzed by western blot as described previously [22]. Briefly, total protein from cells was extracted using RIPA buffer (Beyotime) and protein concentrations were determined using the BCA kit (Beyotime). Twenty micrograms of total protein extracts was resolved by $10 \%$ SDS-PAGE and then subsequently 


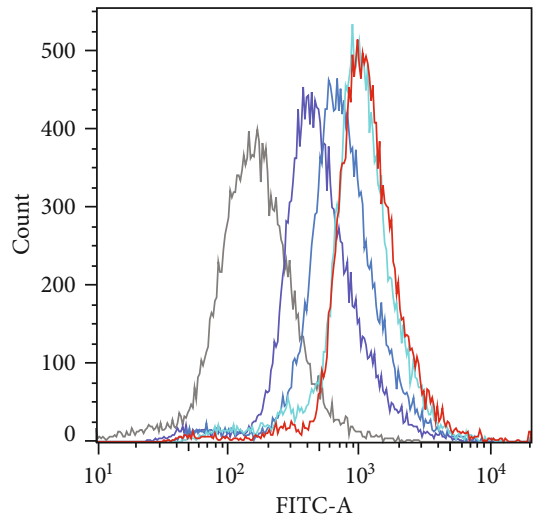

SampleID

$\square$ Control

$\square$ Phloretin $25 \mu \mathrm{M}$

$\square$ Phloretin $50 \mu \mathrm{M}$

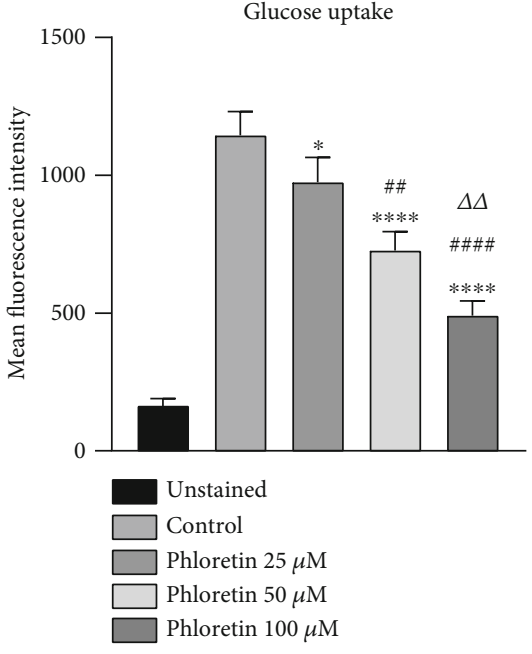

(a)

Anti-CD3/CD28

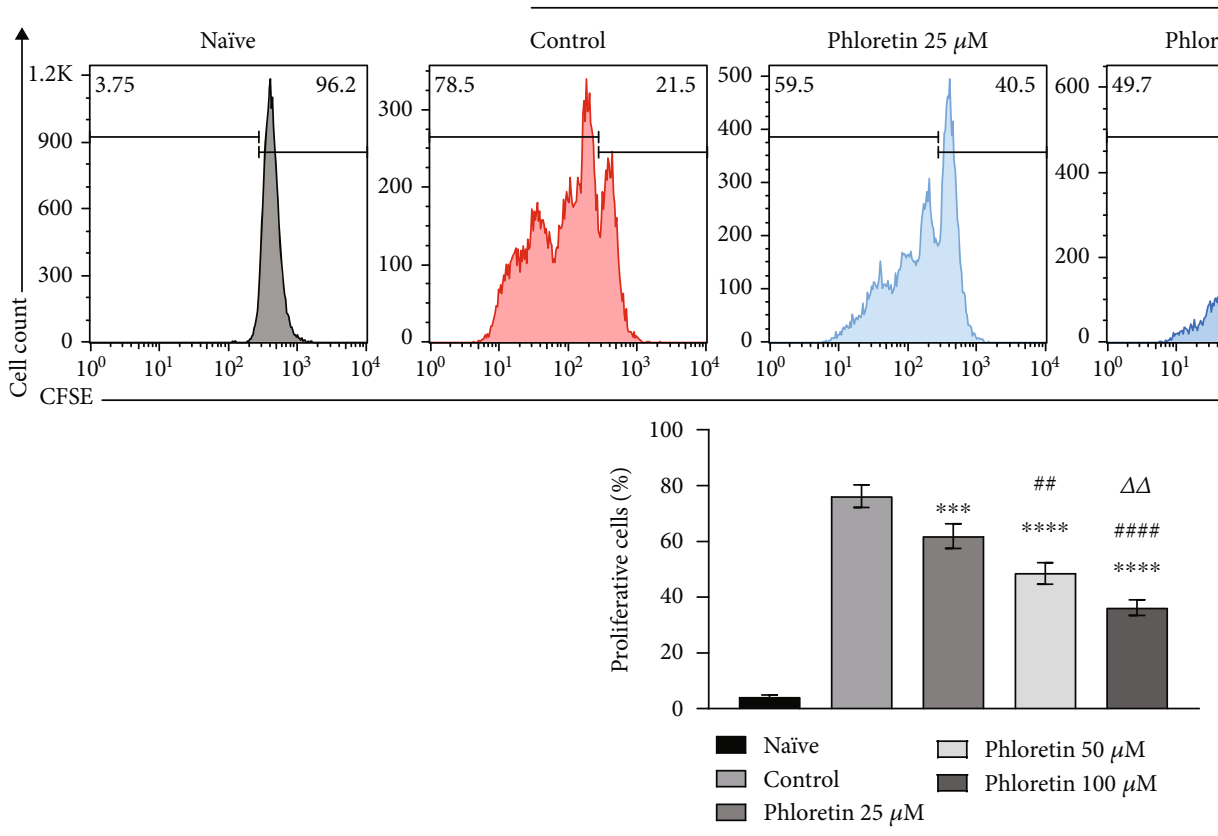

(b)

FIgURE 1: Continued. 

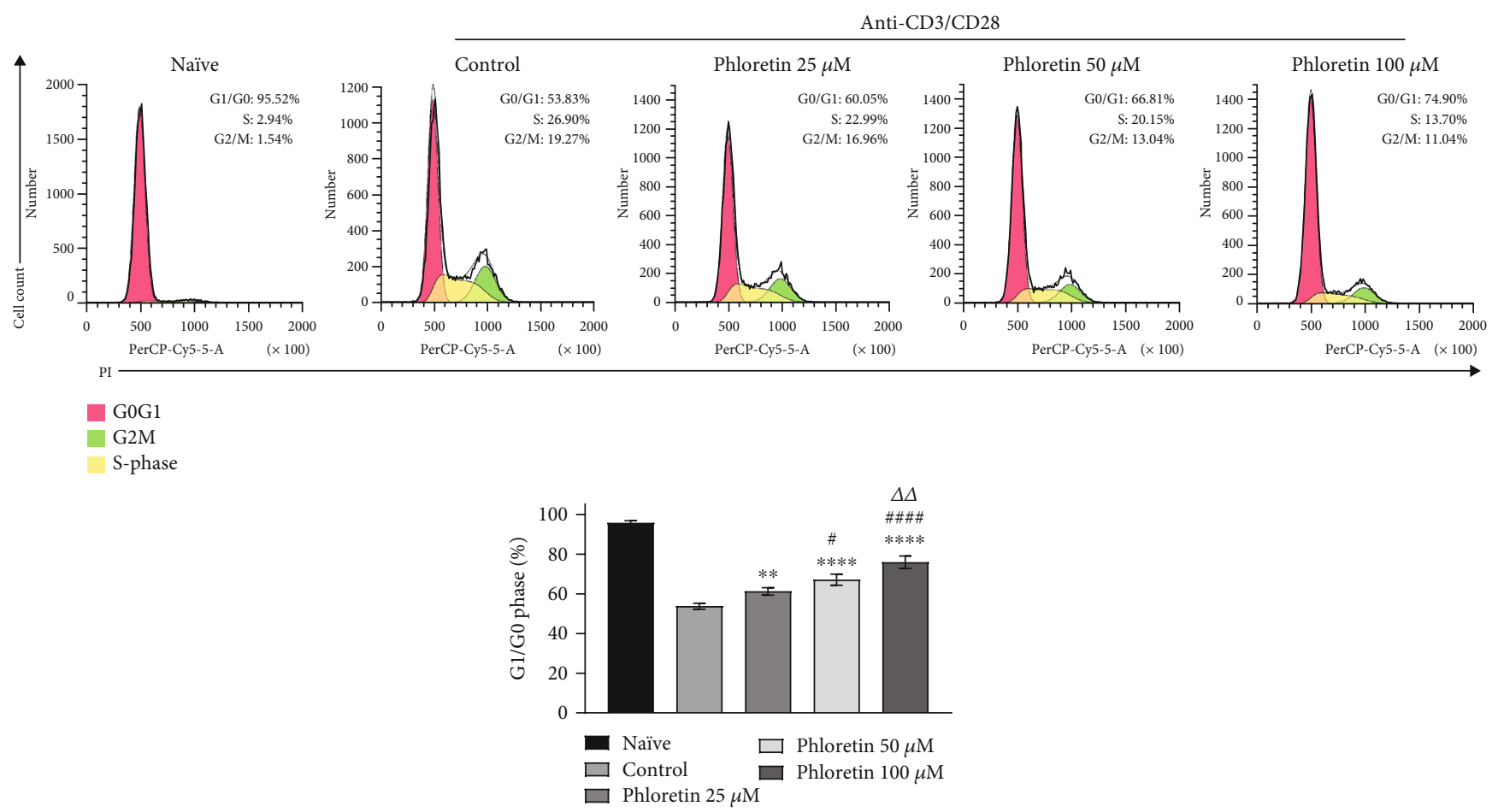

(c)

Figure 1: Glucose uptake and proliferation of $\mathrm{CD}^{+} \mathrm{T}$ cells were inhibited by phloretin. (a) Glucose uptake of anti-CD3/CD28-activated $\mathrm{CD}^{+} \mathrm{T}$ cells was measured using 2 -NBDG staining and flow cytometry in the presence or absence of phloretin $(25 \mu \mathrm{M}, 50 \mu \mathrm{M}$, and $100 \mu \mathrm{M}) .{ }^{*} p<0.05$ and ${ }^{* * * *} p<0.0001$ versus the control group; ${ }^{\# \#} p<0.01$ and ${ }^{\# \# \# \#} p<0.0001$ versus the $25 \mu \mathrm{M}$ phloretin treatment group; ${ }^{\Delta \Delta} p<0.01$ versus the $50 \mu \mathrm{M}$ phloretin treatment group (mean $\left.\pm \mathrm{SD}, n=4\right)$. (b) Cell proliferation of naïve and anti-CD3/CD28-activated $\mathrm{CD}^{+} \mathrm{T}$ cells was measured in the presence of phloretin $(25,50$, and $100 \mu \mathrm{M})$ using CFSE staining kits and flow cytometry. ${ }^{* * *} p<0.001$ and ${ }^{* * * *} p<0.0001$ versus the control group; ${ }^{\# \#} p<0.01$ and ${ }^{\# \# \# \#} p<0.0001$ versus the $25 \mu \mathrm{M}$ phloretin treatment group; ${ }^{\Delta \Delta} p<0.01$ versus the $50 \mu \mathrm{M}$ phloretin treatment group (mean $\pm \mathrm{SD}, n=4$ ). (c) Cell cycle of naïve and anti-CD3/CD28-activated CD $4^{+} \mathrm{T}$ cells was measured in the presence of phloretin $(25,50$, and $100 \mu \mathrm{M})$ using PI staining and flow cytometry. ${ }^{* *} p<0.01$ and ${ }^{* * * *} p<0.0001$ versus the control group; ${ }^{\#} p<0.05$ and ${ }^{\# \# \#} p<0.0001$ versus the $25 \mu \mathrm{M}$ phloretin treatment group; ${ }^{\Delta \Delta} p<0.01$ versus the $50 \mu \mathrm{M}$ phloretin treatment group (mean $\pm \mathrm{SD}, n=4)$. (a-c) The control group was treated with DMSO, and one-way ANOVA followed by Tukey's multiple comparison test was used in each statistical analysis.

electroblotted onto PVDF membranes. Blots were blocked with 5\% nonfat milk (Boster Biological Technology, Wuhan, China) for $30 \mathrm{~min}$ and then probed with 1: 4000-diluted rabbit beta-actin antibody (20536-1-AP, Proteintech), or 1: 1000-diluted AMPK $\alpha$ antibody (2532, CST), or 1: 1000diluted phospho-AMPK $\alpha$ (Thr172) antibody (2535, CST), or 1: 1000-diluted mTOR antibody (2972, CST), or 1: 1000diluted phospho-mTOR antibody (2971, CST), and incubated overnight at $4^{\circ} \mathrm{C}$, followed by horseradish peroxidaseconjugated secondary antibodies for $1.5 \mathrm{~h}$ at room temperature. Proteins were visualized using ECL reagent (Beyotime). The results were scanned using the Bio-Rad Gel Doc XR+ System, and densitometric analysis of the scanned images was performed using the ImageJ software (version 1.52).

2.9. Statistical Analysis. Data were expressed as mean \pm standard deviations (SD). The differences between means and the effects of treatments were analyzed by Student's unpaired $t$-test with two-tailed $p$ values and one-way ANOVA followed by Tukey's multiple comparison test, using GraphPad Prism 8 (GraphPad Software, Inc., USA). A probability $(p)$ value $<0.05$ was considered to be statisti- cally significant. All experiments were performed at least three times.

\section{Results}

3.1. Phloretin Can Inhibit Glucose Uptake and Proliferation of Activated $\mathrm{CD}^{+} \mathrm{T}$ Cell. To investigate whether phloretin could block glucose transport in $\mathrm{CD} 4^{+} \mathrm{T}$ cells, we detected glucose uptake using a flow cytometer following treatment with phloretin. The results showed that phloretin significantly decreased glucose uptake in $\mathrm{CD}^{+}{ }^{+} \mathrm{T}$ cells activated by CD3/CD28 antibody (Figure 1(a)). The effect of phloretin on $\mathrm{CD}^{+} \mathrm{T}$ cell proliferation was further examined. The CFSE staining results showed that phloretin significantly inhibited the proliferation of activated $\mathrm{CD}^{+} \mathrm{T}$ cells in a concentration-dependent manner (Figure 1(b)). In addition, we found that the cell cycle of activated $\mathrm{CD} 4^{+} \mathrm{T}$ cells was inhibited in the G0/G1 phase by phloretin (Figure 1(c)).

3.2. Phloretin Influences the Differentiation of Th17 and Treg Cells In Vitro. We stimulated purified naïve $\mathrm{CD}^{+} \mathrm{T}$ cells in vitro with Th17-polarizing conditions or Treg-polarizing 
Th17-polarizing conditions

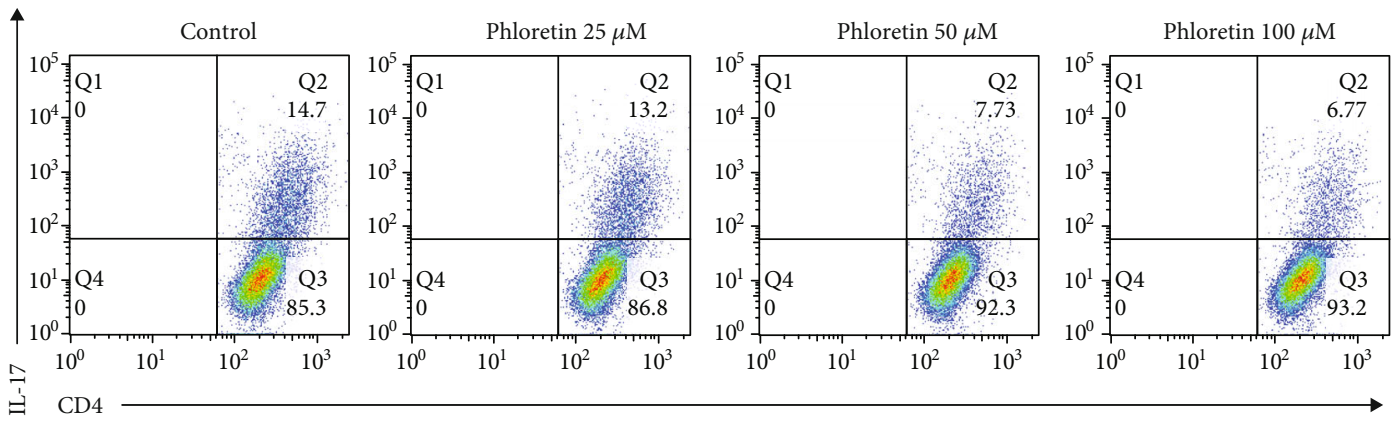

(a)

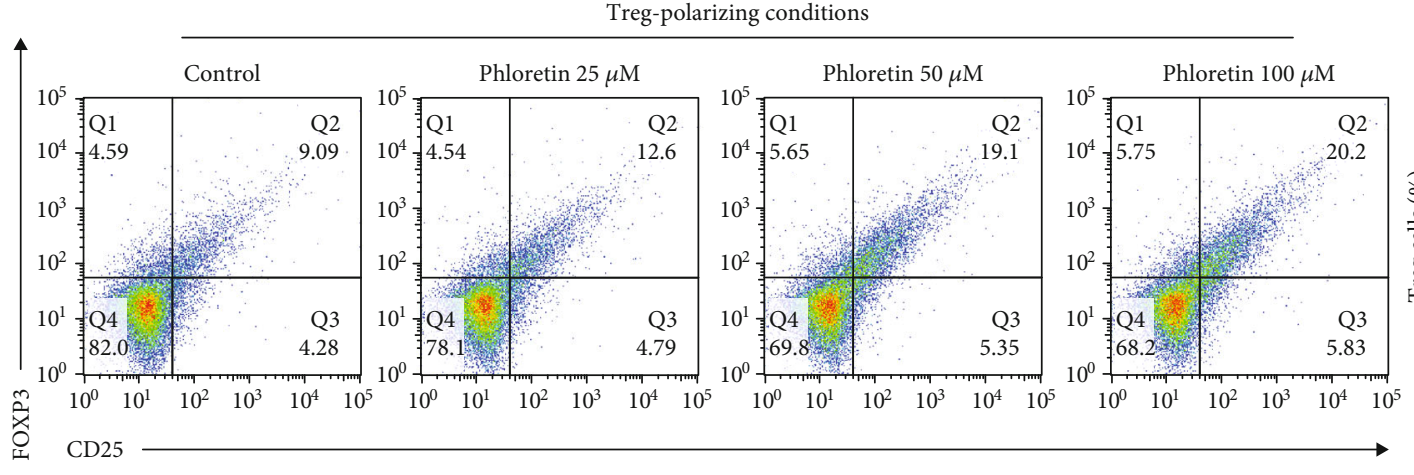

(b)

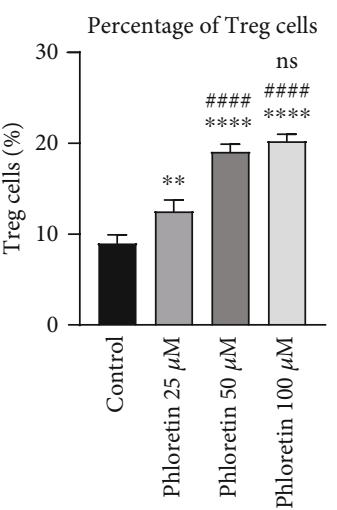

Figure 2: Continued. 

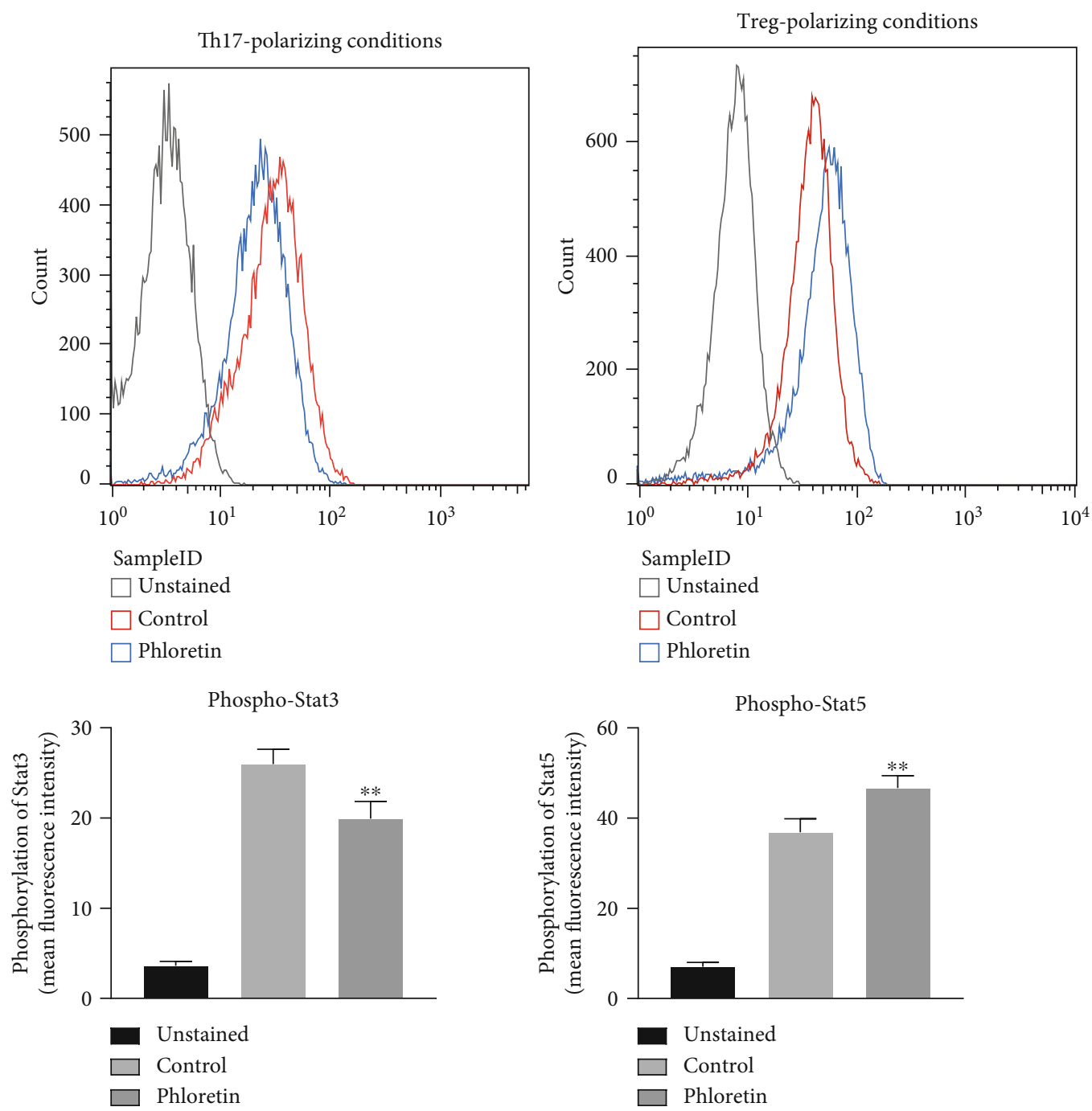

(c)

FIgure 2: Phloretin influences the differentiation of Th17 and Treg cells in vitro. (a) The frequency of Th17 cells generated under Th17 polarization conditions in the presence or absence of phloretin $(25,50$, and $100 \mu \mathrm{M})$ using fluorescent antibody staining and flow cytometry. ${ }^{*} p<0.05$ and ${ }^{* * * *} p<0.0001$ versus the control group; ${ }^{\# \# \#} p<0.0001$ versus the $25 \mu \mathrm{M}$ phloretin treatment group; ns means no significant difference between the $50 \mu \mathrm{M}$ and $100 \mu \mathrm{M}$ phloretin treatment group (mean $\pm \mathrm{SD}, n=4$, one-way ANOVA followed by Tukey's multiple comparison test). (b) The frequency of Treg cells generated under Treg polarization conditions in the presence or absence of phloretin $(25,50$, and $100 \mu \mathrm{M})$ using fluorescent antibody staining and flow cytometry. ${ }^{* *} p<0.01$ and ${ }^{* * * *} p<0.0001$ versus the control

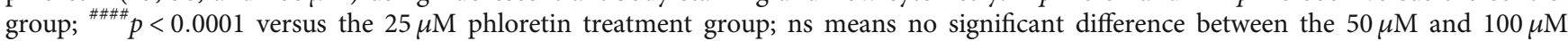
phloretin treatment group (mean $\pm \mathrm{SD}, n=4$, one-way ANOVA followed by Tukey's multiple comparison test). (c) Expression levels of phospho-Stat 3 or phospho-Stat5 were examined under Th17 or Treg polarization conditions in the presence or absence of phloretin $(50 \mu \mathrm{M})$ using fluorescent antibody staining and flow cytometry. ${ }^{* *} p<0.01$ versus the control group (mean $\pm \mathrm{SD}, n=4$, Student's unpaired $t$-test). (a-c) The control group was treated with DMSO.

conditions with different concentrations of phloretin. After 3 -day culture, the frequency of Th17 cells and Treg cells was tested by flow cytometry. As Figure 2(a) showed, the cell count of Th17 cells was significantly reduced when cultured with phloretin. In contrast, the number of Treg cells was significantly increased when exposed to phloretin (Figure 2(b)). These results showed that phloretin could influence the differentiation of Th17 and Treg cells. In addition, $50 \mu \mathrm{M}$ and $100 \mu \mathrm{M}$ phloretin can bring greater effect in impacting differentiation of Th17 and Treg cell compared to $25 \mu \mathrm{M}$ phloretin $(p<0.0001)$. In consideration of the proliferation inhibition effect for activated $\mathrm{CD} 4^{+} \mathrm{T}$ cells and the same effect (no significant difference) between $50 \mu \mathrm{M}$ and $100 \mu \mathrm{M}$ phloretin on the differentiation of Th17 and Treg cell, $50 \mu \mathrm{M}$ phloretin was believed to be more suitable for the follow-up research. Stimulation by IL-6 leads to the activation of Stat 3 which is a key signal molecule for Th17 cell differentiation [23]. IL-2/Stat5 signaling is critically required for Treg development and Foxp3 expression [24]. Thus, the expression of phospho-Stat 3 and phospho-Stat5 was analyzed further by flow cytometry. Figure 2(c) showed that phloretin could inhibit the phosphorylation of Stat3 and promote the 


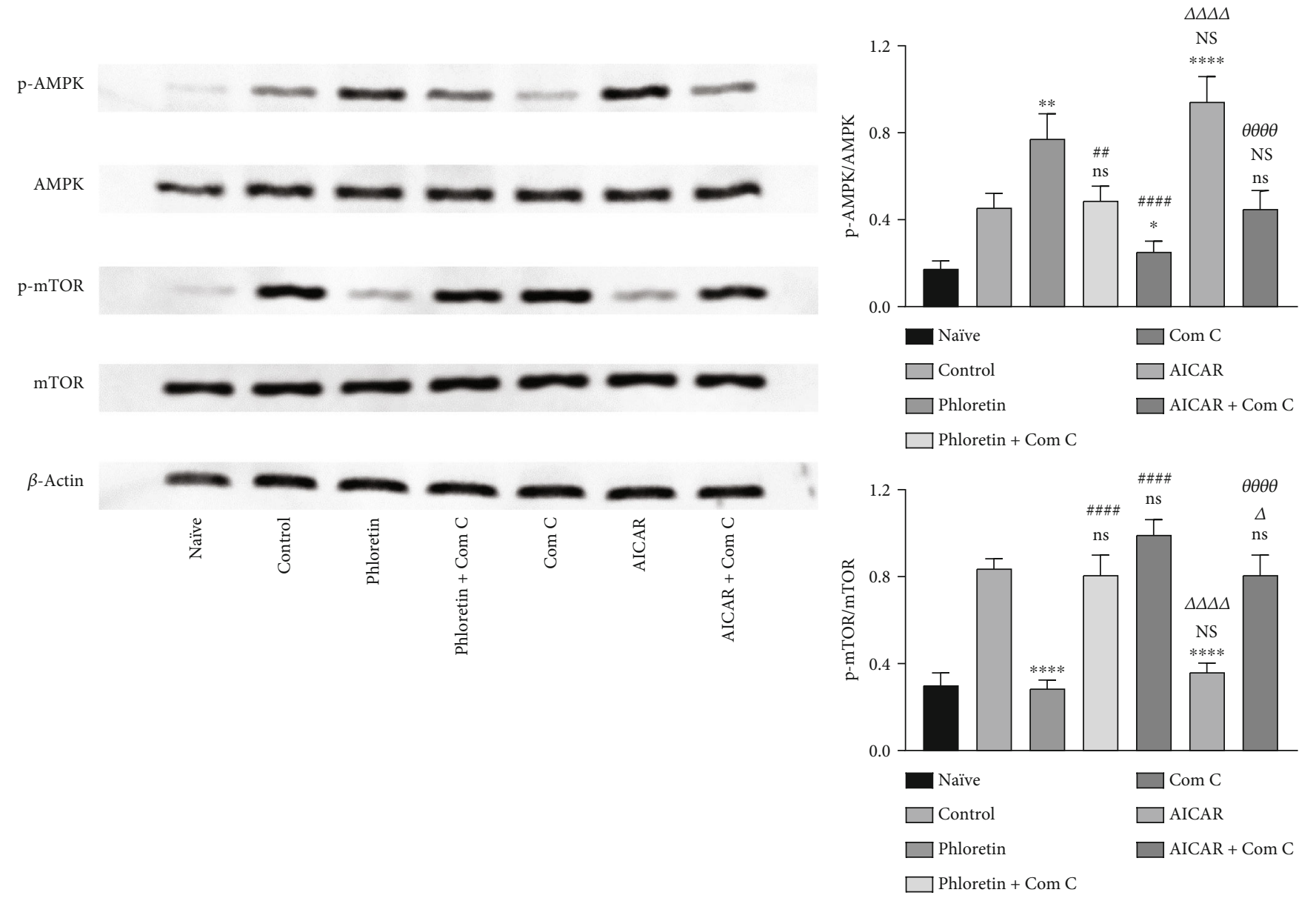

Figure 3: Continued. 
Th17-polarizing conditions

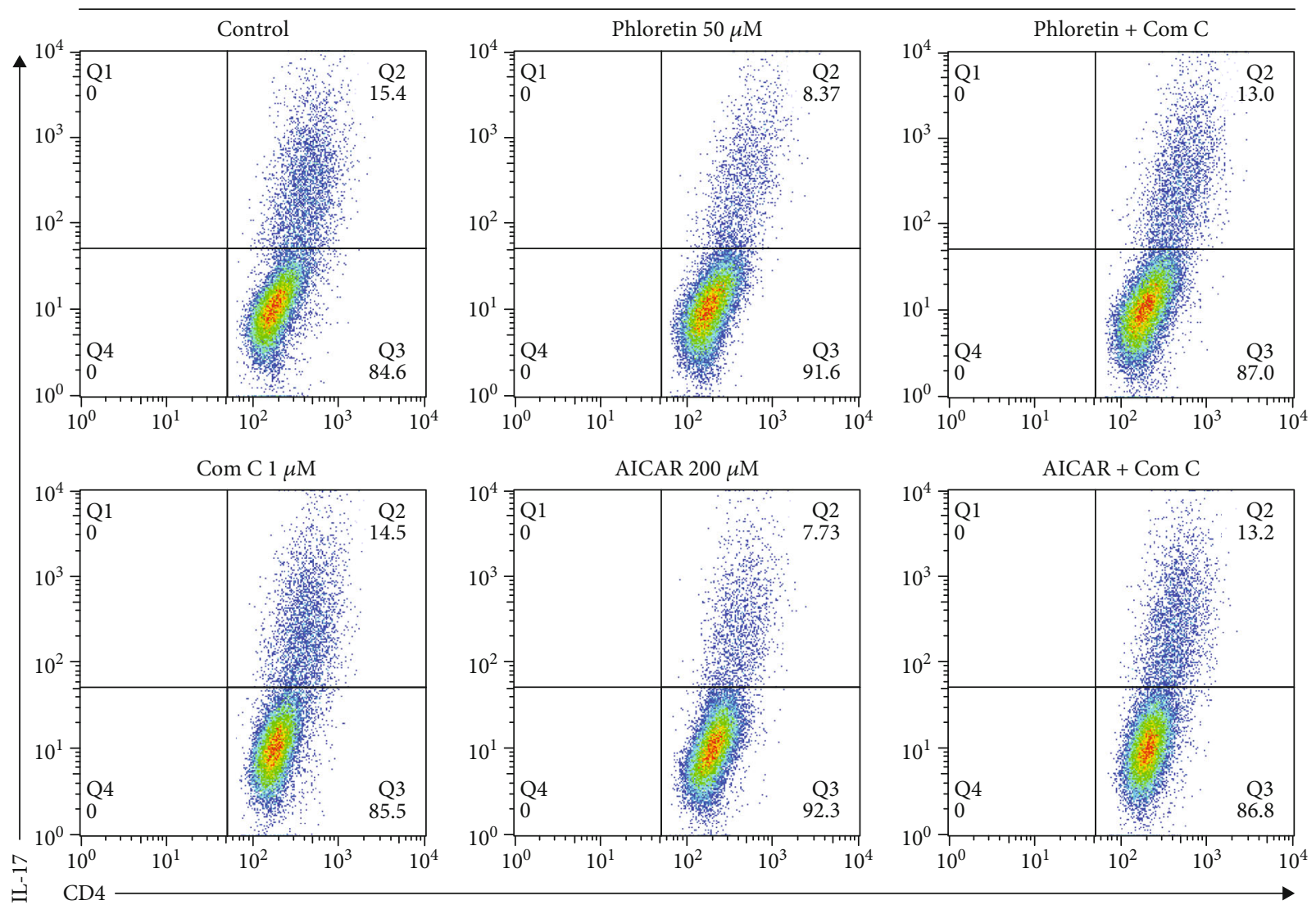

Percentage of Th17 cells

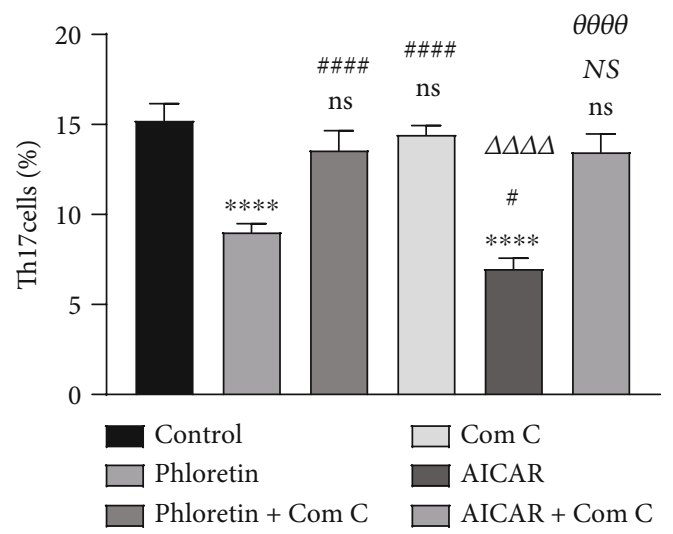

(b)

Figure 3: Continued. 

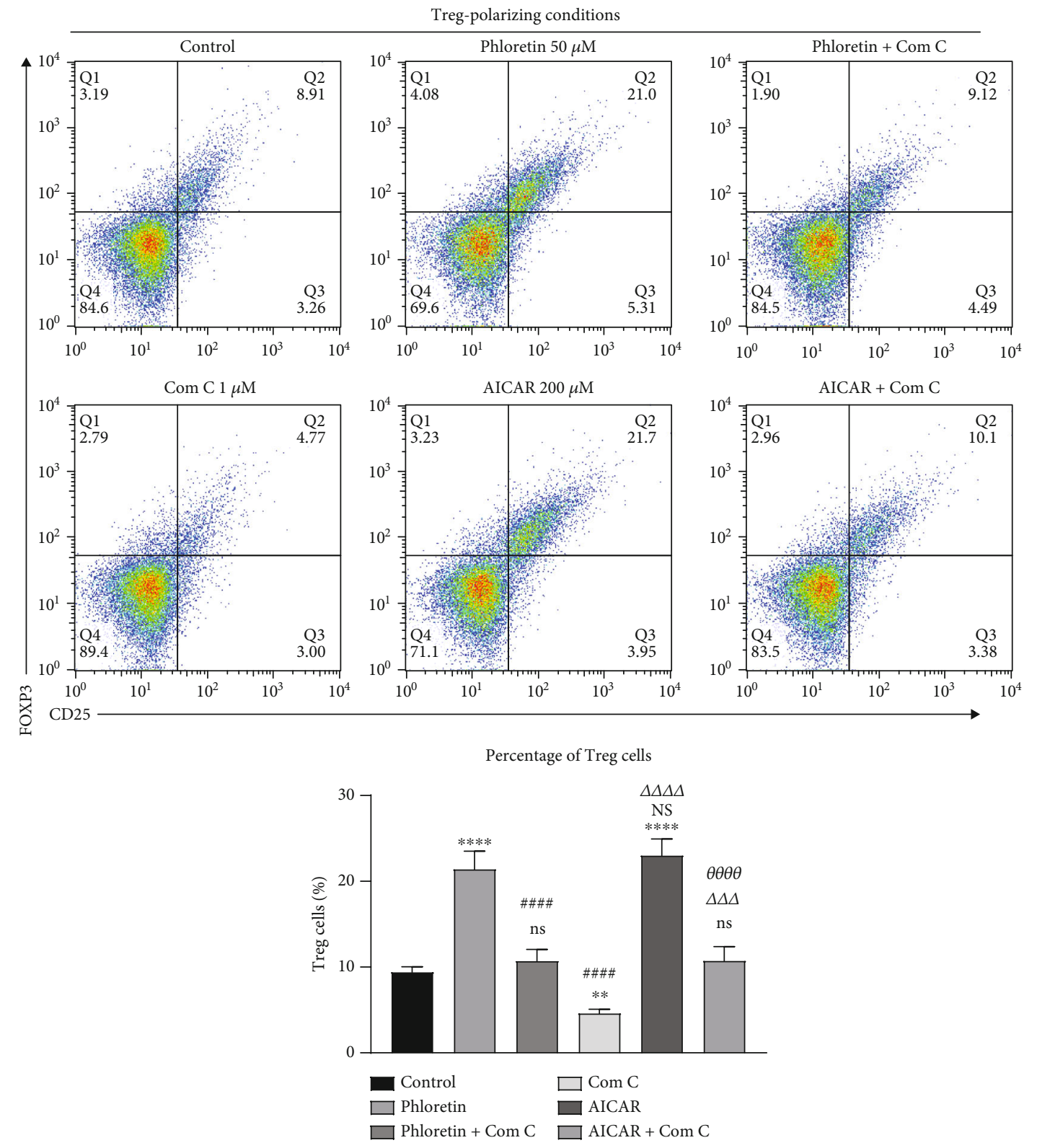

(c)

FIgURE 3: Phloretin influences Th17/Treg differentiation via glycolysis AMPK signaling. (a) The effect of phloretin on the expression of phosphorylated AMPK and mTOR was detected by western blot in activated $\mathrm{CD} 4^{+} \mathrm{T}$ cells. After naïve CD4 ${ }^{+} \mathrm{T}$ cells were activated, DMSO, $50 \mu \mathrm{M}$ phloretin, $50 \mu \mathrm{M}$ phloretin combined with $1 \mu \mathrm{M}$ Com C, $1 \mu \mathrm{M}$ Com C, $200 \mu \mathrm{M}$ AICAR, and $200 \mu \mathrm{M}$ AICAR combined with $1 \mu \mathrm{M}$ Com $\mathrm{C}$ were added to the culture medium, respectively, and activated CD $4^{+} \mathrm{T}$ cells were continuously cultured for $6 \mathrm{~h}$. Total AMPK and beta-actin were used as loading control, respectively. ${ }^{*} p<0.05,{ }^{* *} p<0.01,{ }^{* * * *} p<0.0001$, and ns (no significant difference) versus the control group; ${ }^{\# \#} p<0.01,{ }^{\# \# \# \#} p<0.0001$, and NS (no significant difference) versus the phloretin treatment group; ${ }^{\Delta} p<0.05$, ${ }^{\Delta \Delta \Delta \Delta} p<0.0001$, and NS (no significant difference) versus the Com C treatment group; ${ }^{\theta \theta \theta \theta} p<0.0001$ versus the AICAR treatment group (mean $\pm \mathrm{SD}, n=4$ ). (b) The frequency of Th17 cells generated under Th17 polarization conditions. After naïve CD4 ${ }^{+} \mathrm{T}$ cells were activated, DMSO, $50 \mu \mathrm{M}$ phloretin, $50 \mu \mathrm{M}$ phloretin combined with $1 \mu \mathrm{M}$ Com C, $1 \mu \mathrm{M}$ Com C, $200 \mu \mathrm{M}$ AICAR, and $200 \mu \mathrm{M}$ AICAR combined with $1 \mu \mathrm{M}$ Com $\mathrm{C}$ were added to Th17-polarization culture medium, respectively, and cells were continuously cultured for 3 days. ${ }^{* * * *} p<0.0001$ and ns versus the control group; ${ }^{\#} p<0.05$ and ${ }^{\# \# \# \#} p<0.0001$ versus the phloretin treatment group; ${ }^{\Delta \Delta \Delta \Delta} p<0.0001$ and NS versus the Com C treatment group; ${ }^{\theta \theta \theta} p<0.0001$ versus the AICAR treatment group (mean \pm SD, $\left.n=4\right)$. (c) The frequency of Treg cells generated under Treg polarization conditions. After naïve $\mathrm{CD}^{+} \mathrm{T}$ cells were activated, DMSO, $50 \mu \mathrm{M}$ phloretin, $50 \mu \mathrm{M}$ phloretin combined with $1 \mu \mathrm{M}$ Com C, $1 \mu \mathrm{M}$ Com C, $200 \mu \mathrm{M}$ AICAR, and $200 \mu \mathrm{M}$ AICAR combined with $1 \mu \mathrm{M}$ Com C were added to Treg polarization culture medium, respectively, and cells were continuously cultured for 3 days. ${ }^{* *} p<0.01,{ }^{* * * *} p<0.0001$, and ns versus

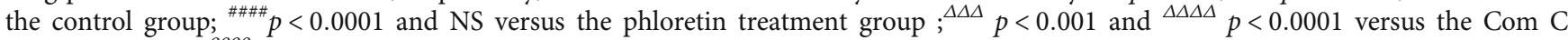
treatment group; ${ }^{\theta \theta \theta \theta} p<0.0001$ versus the AICAR treatment group (mean $\pm \mathrm{SD}, n=4$ ). (a-c) One-way ANOVA followed by Tukey's multiple comparison test was used in each statistical analysis. 
phosphorylation of Stat5 in the process of $\mathrm{CD}^{+} \mathrm{T}$ cell polarization. These data indicated that phloretin could inhibit Th17 cell development while promoting Treg cell differentiation.

3.3. Phloretin Influences Th17/Treg Differentiation via Glycolysis AMPK Signaling. Previous studies demonstrated that AMPK was the key signal pathway to decide the differentiation direction of $\mathrm{T}$ cell $[17,20,25]$. Western blot results showed that phloretin could promote the phosphorylation of AMPK, while it decreased the phosphorylation level of mTOR in activated $\mathrm{CD}^{+} \mathrm{T}$ cells (Figure $3(\mathrm{a})$ ). In addition, AMPK signaling inhibitor Com $\mathrm{C}$ could reverse the effect of phloretin. Flow cytometry results showed that Com C could attenuate the effect of phloretin during induction of Th17/Treg differentiation, while the AMPK signaling agonist AICAR could impact the Th17/Treg development similar to phloretin (Figures 3(b) and 3(c)). These data indicated that phloretin could influence Th17/Treg differentiation balance via glycolysis AMPK signaling.

\section{Discussion}

Keeping appropriate immune homeostasis and self-tolerance is necessary for health. The anti-inflammatory effect of phloretin has been shown in animals and in vitro [12]. However, whether $\mathrm{T}$ cell immunity is influenced by phloretin is not completely clear. Therefore, we examined the impact and signaling mechanisms of phloretin on Th17/Treg development.

First, we confirmed that phloretin significantly decreased glucose uptake and inhibited proliferation in $\mathrm{CD} 4^{+} \mathrm{T}$ cells activated by anti-CD3/CD28 antibody. Moreover, the proliferation inhibition of activated $\mathrm{CD} 4^{+} \mathrm{T}$ cells was due to the G0/G1 phase arrest under phloretin treatment. Further, phloretin decreased Th17 cell generation and phosphoStat3 expression as well as increased Treg cell generation and phospho-Stat5 expression in the process of inducing Th17/Treg differentiation. These results prompted us to further examine phloretin's mechanism of action in $\mathrm{CD}^{+} \mathrm{T}$ cell differentiation.

AMPK is an important sensor of energy and nutrient status in eukaryotic cells. AMPK can feel changes in the ratio of AMP : ATP; if the ratio increasing (energy deficit) is detected, AMPK will be activated and tune on alternate catabolic pathways to restore energy homeostasis, while tuning off biosynthetic pathways and other nonessential processes [26]. In addition, AMPK is a key regulator of mTOR. Energy deprivation-induced AMPK activation will inhibit mTOR signaling [27].

Stat 3 and Stat 5 are important regulators of Th17/Treg cell differentiation. Activated Stat 3 promotes Th17 cell differentiation via inducing RoRyt and IL-17 expression [28]. In addition, HiF1 $\alpha$ whose activity is regulated by Stat3 [29] modulates Th17/Treg differentiation [30]. On the contrary, activated Stat 5 regulates Treg differentiation cell through promoting Foxp3 expression [31]. Both Stat3 and Stat5 are regulated by mTOR; mTOR signaling can activate Stat 3 and inhibit Stat5 [32].

Phloretin can broadly activate the AMPK pathway in most cells, such as murine preadipocytes [33], murine lung fibroblasts [34], murine osteocytes [35], mouse marrow stromal cells [36], and human umbilical vein endothelial cells (HUVECs) [37]. In this study, the phosphorylation level of AMPK was significantly enhanced and the phosphorylation level of mTOR was significantly reduced in human activated $\mathrm{CD} 4^{+} \mathrm{T}$ cells under phloretin treatment. The AMPK signaling inhibitor Com $C$ could neutralize the effect of phloretin during Th17/Treg cell induction, while the AMPK agonist AICAR could impact the Th17/Treg balance similar to phloretin. These results indicated that phloretin modulated Th17/Treg differentiation balance via AMPK signaling.

Phloretin is usually used as sodium-glucose linked transporter (SGLT) inhibitor. Based on this, phloretin exhibits anticancer activity in vitro and in vivo. However, whether phloretin can be used as a clinical antitumor drug still requires further research. Although the interaction between the immune system and cancer has been studied for more than a century, in recent years, the field has realized the great potential of stimulating the immune system to eradicate cancer [38]. Antitumor treatments that currently block monoclonal antibodies at the combined immunization checkpoint continue to produce exciting results [39]. Our results of this study suggest that phloretin has inhibitory effects on T cell immunity, and it may not be a good anticancer drug component. However, the dual effects of immunosuppressive and antitumor effects of phloretin are more suitable as immunosuppressive drugs for liver transplantation in patients with hepatocellular carcinoma or kidney transplantation in patients with renal cancer, just like rapamycin (a kind of mTOR inhibitor) [40,41]. But these conclusions also need further research in vivo.

In summary, phloretin inhibits activated $\mathrm{CD} 4^{+} \mathrm{T}$ cell proliferation, suppresses Th17 cell development, and prompts Treg cell differentiation. Additionally, phloretin mediates the Th17/Treg cell balance by regulating metabolism via the AMPK signal pathway. Consequently, these findings may help the development of new drugs based on phloretin for immune diseases and cancer.

\section{Data Availability}

The data used to support the findings of this study are available from the corresponding author upon request.

\section{Conflicts of Interest}

The authors declare that they have no conflicts of interest.

\section{Acknowledgments}

This work was supported by the Natural Foundation Plan of Liaoning Province (2019-BS-297).

\section{References}

[1] A. Picinelli, E. Dapena, and J. J. Mangas, "Polyphenolic pattern in apple tree leaves in relation to scab resistance. A preliminary study," Journal of Agricultural and Food Chemistry, vol. 43, no. 8, pp. 2273-2278, 1995. 
[2] B. M. Rezk, G. R. M. M. Haenen, W. J. F. van der Vijgh, and A. Bast, "The antioxidant activity of phloretin: the disclosure of a new antioxidant pharmacophore in flavonoids," Biochemical and Biophysical Research Communications, vol. 295, no. 1, pp. 9-13, 2002.

[3] C. Oresajo, T. Stephens, P. D. Hino et al., "Protective effects of a topical antioxidant mixture containing vitamin $\mathrm{C}$, ferulic acid, and phloretin against ultraviolet-induced photodamage in human skin," Journal of Cosmetic Dermatology, vol. 7, no. 4, pp. 290-297, 2008.

[4] S. V. Abkin, O. S. Ostroumova, E. Y. Komarova et al., "Phloretin increases the anti-tumor efficacy of intratumorally delivered heat-shock protein $70 \mathrm{kDa}$ (HSP70) in a murine model of melanoma," Cancer Immunology, Immunotherapy : CII., vol. 65, no. 1, pp. 83-92, 2016.

[5] S. Nam, S. Y. Lee, and H. J. Cho, "Phloretin-loaded fast dissolving nanofibers for the locoregional therapy of oral squamous cell carcinoma," Journal of Colloid and Interface Science, vol. 508, pp. 112-120, 2017.

[6] H. Kum, K. B. Roh, S. Shin, K. Jung, D. Park, and E. Jung, "Evaluation of anti-acne properties of phloretin in vitro and in vivo," International Journal of Cosmetic Science, vol. 38, no. 1, pp. 85-92, 2016.

[7] J. Wang, B. Liu, Z. Teng et al., "Phloretin attenuates listeria monocytogenes virulence both in vitro and in vivo by simultaneously targeting listeriolysin $\mathrm{O}$ and sortase A," Frontiers in Cellular and Infection Microbiology, vol. 7, p. 9, 2017.

[8] X. Shen, N. Zhou, L. Mi et al., "Phloretin exerts hypoglycemic effect in streptozotocin-induced diabetic rats and improves insulin resistance in vitro," Drug Design, Development and Therapy, vol. Volume11, pp. 313-324, 2017.

[9] V. Stangl, M. Lorenz, A. Ludwig et al., "The flavonoid phloretin suppresses stimulated expression of endothelial adhesion molecules and reduces activation of human platelets," The Journal of Nutrition, vol. 135, no. 2, pp. 172-178, 2005.

[10] Y. Ying, C. Jiang, M. Zhang, J. Jin, S. Ge, and X. Wang, "Phloretin protects against cardiac damage and remodeling via restoring SIRT1 and anti-inflammatory effects in the streptozotocin-induced diabetic mouse model," Aging, vol. 11, no. 9, pp. 2822-2835, 2019.

[11] J. B. Fordham, A. Raza Naqvi, and S. Nares, "Leukocyte production of inflammatory mediators is inhibited by the antioxidants phloretin, silymarin, hesperetin, and resveratrol," Mediators of Inflammation, vol. 2014, Article ID 938712, 11 pages, 2014.

[12] J. Kim, P. Durai, D. Jeon et al., "Phloretin as a potent natural TLR2/1 inhibitor suppresses TLR2-induced inflammation," Nutrients, vol. 10, no. 7, p. 868, 2018.

[13] G. R. Lee, "The balance of Th17 versus Treg cells in autoimmunity," International Journal of Molecular Sciences, vol. 19, no. 3, p. 730, 2018.

[14] L. A. Tesmer, S. K. Lundy, S. Sarkar, and D. A. Fox, “Th17 cells in human disease," Immunological Reviews, vol. 223, no. 1, pp. 87-113, 2008.

[15] K. Majchrzak, M. H. Nelson, S. R. Bailey et al., "Exploiting IL-17-producing CD4+ and CD8+ T cells to improve cancer immunotherapy in the clinic," Cancer Immunology, Immunotherapy: CII, vol. 65, no. 3, pp. 247-259, 2016.

[16] G. Xia, S. Wu, X. Wang, and M. Fu, "Inhibition of microRNA155 attenuates concanavalin-A-induced autoimmune hepatitis by regulating Treg/Th17 cell differentiation," Canadian
Journal of Physiology and Pharmacology, vol. 96, no. 12, pp. 1293-1300, 2018.

[17] A. Tanaka and S. Sakaguchi, "Regulatory T cells in cancer immunotherapy," Cell Research, vol. 27, no. 1, pp. 109-118, 2017.

[18] A. Angelin, L. Gil-de-Gómez, S. Dahiya et al., "Foxp3 reprograms $\mathrm{T}$ cell metabolism to function in low-glucose, high-lactate environments," Cell Metabolism, vol. 25, no. 6, pp. 1282-1293.e7, 2017.

[19] M. Galgani, V. De Rosa, and G. Matarese, "T cell metabolism and susceptibility to autoimmune diseases," Molecular Immunology, vol. 68, no. 2, pp. 558-563, 2015.

[20] J. Zhang, J. Shan, X. Chen, S. Li, D. Long, and Y. Li, “Celastrol mediates Th17 and Treg cell generation via metabolic signaling," Biochemical and biophysical research communications, vol. 497, no. 3, pp. 883-889, 2018.

[21] X. Qu, J. Han, Y. Zhang et al., "MiR-384 regulates the Th17/Treg ratio during experimental autoimmune encephalomyelitis pathogenesis," Frontiers in Cellular Neuroscience, vol. 11, p. 88, 2017.

[22] A. Jiao, F. Li, C. S. Zhang, W. Lv, B. Chen, and J. Zhang, "Simulated cholinergic reinnervation of $\beta$ (INS-1) cells: antidiabetic utility of heterotypic pseudoislets containing $\beta$ cell and cholinergic cell," International Journal of Endocrinology, vol. 2018, Article ID 1505307, 13 pages, 2018.

[23] S. K. Tripathi, Z. Chen, A. Larjo et al., "Genome-wide analysis of STAT3-mediated transcription during early human Th17 cell differentiation," Cell Reports, vol. 19, no. 9, pp. 1888-1901, 2017.

[24] J. Shan, L. Feng, G. Sun et al., "Interplay between mTOR and STAT5 signaling modulates the balance between regulatory and effective T cells," Immunobiology, vol. 220, no. 4, pp. 510-517, 2015.

[25] X. Xu, Y. Wang, Z. Wei et al., "Madecassic acid, the contributor to the anti-colitis effect of madecassoside, enhances the shift of Th17 toward Treg cells via the PPAR $\gamma / \mathrm{AMPK} / \mathrm{ACC} 1$ pathway," Cell Death \& Disease, vol. 8, no. 3, p. e2723, 2017.

[26] D. G. Hardie, "AMPK-sensing energy while talking to other signaling pathways," Cell Metabolism, vol. 20, no. 6, pp. 939952, 2014.

[27] K. Inoki, J. Kim, and K. L. Guan, "AMPK and mTOR in cellular energy homeostasis and drug targets," Annual Review of Pharmacology and Toxicology, vol. 52, no. 1, pp. 381-400, 2012.

[28] X. O. Yang, A. D. Panopoulos, R. Nurieva et al., "STAT3 regulates cytokine-mediated generation of inflammatory helper $\mathrm{T}$ cells," The Journal of Biological Chemistry, vol. 282, no. 13, pp. 9358-9363, 2007.

[29] J. E. Jung, H. G. Lee, I. H. Cho et al., "STAT3 is a potential modulator of HIF-1-mediated VEGF expression in human renal carcinoma cells," FASEB Journal : official publication of the Federation of American Societies for Experimental Biology, vol. 19, no. 10, pp. 1296-1298, 2005.

[30] E. J. Yang, J. Lee, S. Y. Lee et al., "EGCG attenuates autoimmune arthritis by inhibition of STAT3 and HIF- $1 \alpha$ with Th17/Treg control," PLoS One, vol. 9, no. 2, article e86062, 2014.

[31] M. A. Burchill, J. Yang, C. Vogtenhuber, B. R. Blazar, and M. A. Farrar, "IL-2 receptor $\beta$-dependent STAT5 activation is required for the development of Foxp3+ regulatory $\mathrm{T}$ cells," Journal of Immunology, vol. 178, no. 1, pp. 280-290, 2006. 
[32] W. Ren, J. Yin, J. Duan et al., "mTORC1 signaling and IL-17 expression: defining pathways and possible therapeutic targets," European Journal of Immunology, vol. 46, no. 2, pp. 291-299, 2016.

[33] W. C. Huang, W. T. Chang, S. J. Wu, P. Y. Xu, N. C. Ting, and C. J. Liou, "Phloretin and phlorizin promote lipolysis and inhibit inflammation in mouse 3T3-L1 cells and in macrophage-adipocyte co-cultures," Molecular Nutrition \& Food Research, vol. 57, no. 10, pp. 1803-1813, 2013.

[34] S. J. Cho, J. S. Moon, C. M. Lee, A. M. K. Choi, and H. W. Stout-Delgado, "Glucose transporter 1-dependent glycolysis is increased during aging-related lung fibrosis, and phloretin inhibits lung fibrosis," American Journal of Respiratory Cell and Molecular Biology, vol. 56, no. 4, pp. 521-531, 2017.

[35] A. Takeno, I. Kanazawa, M. Notsu, K. I. Tanaka, and T. Sugimoto, "Glucose uptake inhibition decreases expressions of receptor activator of nuclear factor-kappa B ligand (RANKL) and osteocalcin in osteocytic MLO-Y4-A2 cells," American Journal of Physiology Endocrinology and Metabolism, vol. 314, no. 2, pp. E115-E123, 2018.

[36] A. Takeno, I. Kanazawa, M. Notsu, K. I. Tanaka, and T. Sugimoto, "Phloretin promotes adipogenesis via mitogenactivated protein kinase pathways in mouse marrow stromal ST2 cells," International Journal of Molecular Sciences, vol. 19 , no. 6 , p. $1772,2018$.

[37] Q. Yang, L. Han, J. Li et al., "Activation of Nrf2 by phloretin attenuates palmitic acid-induced endothelial cell oxidative stress via AMPK-dependent signaling," Journal of Agricultural and Food Chemistry, vol. 67, no. 1, pp. 120-131, 2018.

[38] J. K. Lee and S. J. Priceman, "Precision medicine-enabled cancer immunotherapy," Cancer Treatment and Research, vol. 178, pp. 189-205, 2019.

[39] E. V. Schmidt, "Developing combination strategies using PD-1 checkpoint inhibitors to treat cancer," Seminars in Immunopathology, vol. 41, no. 1, pp. 21-30, 2019.

[40] D. H. Jung, E. Tak, S. Hwang et al., "Antitumor effect of sorafenib and mammalian target of rapamycin inhibitor in liver transplantation recipients with hepatocellular carcinoma recurrence," Liver Transplantation: official publication of the American Association for the Study of Liver Diseases and the International Liver Transplantation Society, vol. 24, no. 7, pp. 932-945, 2018.

[41] G. M. Frascà, S. Sandrini, L. Cosmai et al., "Renal cancer in kidney transplanted patients," Journal of Nephrology, vol. 28, no. 6, pp. 659-668, 2015. 